\title{
Cholinergic Nociceptive Mechanisms in Rat Meninges and Trigeminal Ganglia: Potential Implications for Migraine Pain
}

\author{
Irina Shelukhina ${ }^{1,2 \dagger}$, Nikita Mikhailov ${ }^{1 \dagger}$, Polina Abushik ${ }^{1}$, Leniz Nurullin ${ }^{3,4}$, \\ Evgeny E. Nikolsky ${ }^{3,4}$ and Rashid Giniatullin ${ }^{1,5 *}$
}

'Department of Neurobiology, A. I. Virtanen Institute for Molecular Sciences, University of Eastern Finland, Kuopio, Finland, ${ }^{2}$ Shemyakin-Ovchinnikov Institute of Bioorganic Chemistry, Russian Academy of Sciences, Moscow, Russian Federation, ${ }^{3}$ Laboratory of Biophysics of Synaptic Processes, Kazan Institute of Biochemistry and Biophysics, Kazan, Russian Federation, ${ }^{4}$ Open Laboratory of Neuropharmacology, Kazan Federal University, Kazan, Russian Federation, ${ }^{5}$ Laboratory of Neurobiology, Kazan Federal University, Kazan, Russian Federation

OPEN ACCESS

Edited by:

Anna Andreou,

Imperial College London, UK

Reviewed by:

Greg Dussor,

University of Texas at Dallas, USA

Mária Dux,

University of Szeged, Hungary

*Correspondence:

Rashid Giniatullin

rashid.giniatullin@uef.fi

tThese authors have contributed equally to this work.

Specialty section: This article was submitted to Headache Medicine and Facial Pain, a section of the journal

Frontiers in Neurology

Received: 10 February 2017 Accepted: 07 April 2017

Published: 27 April 2017

Citation:

Shelukhina I, Mikhailov N, Abushik P, Nurullin L, Nikolsky EE and Giniatullin R (2017) Cholinergic Nociceptive Mechanisms in Rat Meninges and Trigeminal Ganglia: Potential Implications for Migraine Pain.

Front. Neurol. 8:163. doi: 10.3389/fneur.2017.00163
Background: Parasympathetic innervation of meninges and ability of carbachol, acetylcholine (ACh) receptor (AChR) agonist, to induce headaches suggests contribution of cholinergic mechanisms to primary headaches. However, neurochemical mechanisms of cholinergic regulation of peripheral nociception in meninges, origin place for headache, are almost unknown.

Methods: Using electrophysiology, calcium imaging, immunohistochemistry, and staining of meningeal mast cells, we studied effects of cholinergic agents on peripheral nociception in rat hemiskulls and isolated trigeminal neurons.

Results: Both ACh and carbachol significantly increased nociceptive firing in peripheral terminals of meningeal trigeminal nerves recorded by local suction electrode. Strong nociceptive firing was also induced by nicotine, implying essential role of nicotinic AChRs in control of excitability of trigeminal nerve endings. Nociceptive firing induced by carbachol was reduced by muscarinic antagonist atropine, whereas the action of nicotine was prevented by the nicotinic blocker D-tubocurarine but was insensitive to the TRPA1 antagonist HC-300033. Carbachol but not nicotine induced massive degranulation of meningeal mast cells known to release multiple pro-nociceptive mediators. Enzymes terminating ACh action, acetylcholinesterase (AChE) and butyrylcholinesterase, were revealed in perivascular meningeal nerves. The inhibitor of AChE neostigmine did not change the firing per se but induced nociceptive activity, sensitive to D-tubocurarine, after pretreatment of meninges with the migraine mediator CGRP. This observation suggested the pro-nociceptive action of endogenous ACh in meninges. Both nicotine and carbachol induced intracellular $\mathrm{Ca}^{2+}$ transients in trigeminal neurons partially overlapping with expression of capsaicin-sensitive TRPV1 receptors.

Abbreviations: PD, postnatal day; $\mathrm{ACh}$, acetylcholine; $\mathrm{mAChR}$, muscarinic acetylcholine receptor; nAChR, nicotinic acetylcholine receptor; $\mathrm{AChE}$, acetylcholinesterase; $\mathrm{BuChE}$, butyrylcholinesterase; TG, trigeminal ganglion. 
Conclusion: Trigeminal nerve terminals in meninges, as well as dural mast cells and trigeminal ganglion neurons express a repertoire of pro-nociceptive nicotinic and muscarinic AChRs, which could be activated by the ACh released from parasympathetic nerves. These receptors represent a potential target for novel therapeutic interventions in trigeminal pain and probably in migraine.

Keywords: migraine, acetylcholine, nicotine, acetylcholine receptor, meninges, sensory neurons, mast cells

\section{INTRODUCTION}

In migraine pathophysiology, much attention was traditionally paid to the role of trigeminal innervation of meninges, likely representing a triggering zone for migraine pain (1-3). Peripheral primary afferent excitation is followed by activation of neurons in the trigeminocervical complex (4).

In contrast to trigeminal system, considerably less is known about the functional role of parasympathetic innervation of these tissues. Nevertheless, it has been shown that parasympathetic fibers originating from the parasympathetic sphenopalatine ganglion (SPG) can innervate and interact, via released acetylcholine (ACh), with somatic trigeminal nerves located around essential meningeal vessels (5). Moreover, parasympathetic nociceptive traffic can participate in the reflex connecting the trigeminal nucleus caudalis and SPG (central trigeminal-parasympathetic reflex) to control the meningeal blood flow $(6,7)$.

Electrical stimulation of the SPG can induce one of migrainerelated effects, such as vasodilation and plasma protein extravasation in the dura mater likely mediated by muscarinic ACh receptors (mAChRs) (8). In contrast, the blockade of SPG can reduce migraine features in patients (9). It is also known that carbachol, a typical agonist of ACh receptors (AChRs), can induce headaches, but not migraine-like attacks, in patients with migraine without aura (10). This ACh analog is an effective vasodilator of cranial vessels (11). Moreover, it has been shown (12) that injection of botulinum neurotoxin/A (Botox), which inhibits the exocytosis of $\mathrm{ACh}$, can reduce plasma protein extravasation, a phenomenon often associated with migraine. Interestingly, smokers more often suffer from migraine than non-smokers (13), suggesting a potential pro-nociceptive action of nicotine. Whereas nicotinic ACh receptors (nAChRs) are likely involved in pathophysiology of neuropathic pain (14), the anti-nociceptive rather than pro-nociceptive action of nicotine has been reported in in vivo pain models (15-17). One reason for such discrepancies could be the presence of various molecular targets along sensory pathways for nicotine, which apart from ligand-gated nAChRs can also activate pro-nociceptive TRPA1 receptors $(18,19)$.

It is widely accepted nowadays that the key role in migraine pathology belongs to the neuropeptide CGRP, which is released in venous blood flow during migraine attack (20). Carbachol did not change the release of CGRP from meninges; rather, it produced a depressant effect after the sensitization of meninges with inflammatory mediators (5). Carbachol also released histamine from isolated dura mater (21) suggesting degranulation of local mast cells, which are widely presented in meninges and likely play an important role in migraine pathology (22).
In the current project, using ex vivo rat hemiskull preparation with preserved innervation, we showed that the main AChR agonists, ACh, carbachol, and nicotine, all activated nociceptive firing in meningeal nerves and that carbachol (but not nicotine) induced degranulation of dural mast cells. $\mathrm{Ca}^{2+}$ imaging allowed us to confirm the pro-nociceptive action of nicotine and carbachol at the level of single trigeminal neurons.

\section{MATERIALS AND METHODS}

\section{Animals}

Wistar rats of both sexes from the Animal House of the University of Eastern Finland were used in this study. P9-P13 rats were used for trigeminal cell culture preparation and mast cell degranulation assay, whereas adult (P35-P36) rats were used for electrophysiology and immunohistochemistry.

\section{Electrophysiology}

Preparation of male rat (P35-P36) hemiskulls was performed as published earlier $(23,24)$. Briefly, after decapitation, the skin and muscles were removed from the skull, which was dissected mid-sagitally, and both brain hemispheres were gently removed leaving dura mater untouched with preserved trigeminal innervations. A hemiskull was placed into a recording chamber and was continuously superfused with oxygenated $\left(5 \% \mathrm{CO}_{2} / 95 \% \mathrm{O}_{2}\right)$ artificial cerebrospinal fluid (ACSF) containing (in millimolars): $\mathrm{NaCl} 120, \mathrm{KCl} 3, \mathrm{CaCl}_{2} 2, \mathrm{MgCl}_{2} 1, \mathrm{NaH}_{2} \mathrm{PO}_{4} 1, \mathrm{NaHCO}_{3} 25$, and glucose 10 , pH $7.3(6-7 \mathrm{ml} / \mathrm{min})$. The nervus spinosus, which is a part of the mandibular branch of the trigeminal nerve (25) was exposed by a careful dissection of dura mater and thereafter was placed into a fire-polished recording glass microelectrode filled with ACSF. Investigated substances were applied to the recording chamber for 10-20 min via superfusion. Low-noise digital amplifier (ISO 80, WPI Inc., Sarasota, FL, USA) was used for recordings. Signals were visualized and analyzed with the WinEDR V3.4.6 software (Strathclyde University, Glasgow, UK). Spontaneous and drug-induced action potentials generated in the distal parts of the transected nervus spinosus were recorded at room temperature. Spike frequencies (number of spikes per every $2 \mathrm{~min}$ ) were estimated and analyzed using OriginPro 9.1 software (Microcal, Northampton, MA, USA). For control values, the frequency of spikes during $10 \mathrm{~min}$ prior to drug application was taken.

\section{Immunostaining of Acetylcholinesterase (AChE) and Butyrylcholinesterase (BuChE)}

Isolated male rat dura mater preparations were fixed during $60 \mathrm{~min}$ in $2 \% \mathrm{p}$-formaldehyde (Sigma-Aldrich, USA) and rinsed 
three times for $30 \mathrm{~min}$ in the phosphate buffer (PBS, SigmaAldrich). Then, the preparations were consecutively incubated for $30 \mathrm{~min}$ in $0.3 \%$ Triton X-100 (Sigma-Aldrich) for $15 \mathrm{~min}$ in a solution containing $5 \%$ goat serum (Sigma-Aldrich), $1 \%$ bovine serum albumin (BSA, Sigma-Aldrich), and 0.3\% Triton X-100 and for 15 min in a solution of $1 \%$ BSA and $0.3 \%$ Triton X-100 (solution A). These solutions were based on PBS.

Next, preparations were incubated for $15 \mathrm{~h}$ at $4^{\circ} \mathrm{C}$ in the solution A containing goat polyclonal antibody to AChE (dilution 1:1,000, Santa Cruz Biotechnologies, USA), or mouse monoclonal antibody to BuChE (dilution 1:1,000) and rabbit polyclonal antibodies to the neurofilament NF-H (1:1,000, Santa Cruz Biotechnologies, USA). The preparations were rinsed three times in the solution $\mathrm{A}$ and then incubated for $1 \mathrm{~h}$ at room temperature with the appropriate secondary antibodies conjugated to Alexa Fluor 488 or 647 (Invitrogen, USA) diluted 1:1,000 in the solution A.

After washing in PBS, the preparations were exposed to PBS solution diluted by glycerol (1:1) and used for microscopy $(63 \times$, oil immersion, NA $=1.4)$ with a laser scanning confocal microscope Zeiss LSM 510 Meta (Carl Zeiss, Germany).

\section{Dural Mast Cell Degranulation}

To study the action of cholinergic drugs on degranulation of dural mast cells, hemiskulls of Wistar rats of both sexes were used. One control hemiskull was filled for $20 \mathrm{~min}$ with the basic saline solution (BSS), containing (in millimolars) $152 \mathrm{NaCl}$, $5 \mathrm{KCl}, 10$ HEPES, 10 glucose, $2.6 \mathrm{CaCl}_{2}, 2.1 \mathrm{MgCl}_{2}$ (pH adjusted to 7.4 with $\mathrm{NaOH}$ ), whereas others were filled with BSS containing $50 \mu \mathrm{M}$ carbachol or $100 \mu \mathrm{M}$ nicotine. Then, the hemiskulls were left in $4 \%$ PFA solution for at least $4 \mathrm{~h}$. After that meninges were dissected carefully and placed on a microscope slide, where they were stained with $0.1 \%$ toluidine blue (26). Images of meninges were acquired with Olympus AX70 microscope (20× objective). Homogeneously stained and well-shaped mast cells were classified as non-degranulated, whereas pale poorly stained mast cells as well as mast cells with distorted borders were classified as degranulated $(22,26)$. To study an effect of carbachol and nicotine on mast cells degranulation, 10 randomly chosen, same in different animals, perivascular areas of meninges enriched by mast cells were analyzed (27). Then, total number and number of degranulated mast cells were counted in a blind manner.

\section{Primary Culture of Rat Trigeminal Sensory Neurons}

Trigeminal ganglion (TG) cell cultures were prepared as described previously (28). Briefly, trigeminal ganglia of male rats were isolated, and cells were enzymatically dissociated by trypsin (0.5 mg/ml, Sigma-Aldrich), collagenase (1 mg/ml, SigmaAldrich), and DNAse $(0.2 \mathrm{mg} / \mathrm{ml}$, Sigma-Aldrich) for $20 \mathrm{~min}$. Isolated cells were plated on coverslips coated with poly-L-lysine (0.2 $\mathrm{mg} / \mathrm{ml}$, Sigma-Aldrich, MO, USA) and were cultured in $\mathrm{F} 12$ medium (Gibco, USA) at $37^{\circ} \mathrm{C}, 5 \% \mathrm{CO}_{2}$ for $48 \mathrm{~h}$ prior to an experimental treatment.

\section{Calcium Imaging of Trigeminal Neurons}

Primary TG cells kept in culture for 2 days were rinsed with basic solution (BS) containing (in millimolar) $152 \mathrm{NaCl}, 2.5 \mathrm{KCl}, 10$
HEPES, 10 glucose, $2 \mathrm{CaCl}_{2}, 1 \mathrm{MgCl}_{2}$ (pH adjusted to 7.4) followed by loading with $2 \mu \mathrm{M}$ fluo-3 acetoxymethyl ester (Invitrogen, USA) at $37^{\circ} \mathrm{C}$ for $45 \mathrm{~min}$ in BS. After $20 \mathrm{~min}$ postincubation, dishes were transferred to TILL Photonics imaging system (TILL Photonics $\mathrm{GmbH}$, Munich, Germany) and were constantly perfused (at $1.2 \mathrm{ml} / \mathrm{min}$ ) with BS. The setup was equipped by fast perfusion system (Rapid Solution Changer RSC-200, BioLogic Science Instruments, Grenoble, France), which allowed rapid (exchange time $\sim 30 \mathrm{~ms}$ ) application of various compounds. Cells were viewed via Olympus IX-70 (Tokyo, Japan) microscope with a specific filter of $488 \mathrm{~nm}$ wavelength using $10 \times$ objective. Images were collected using CCD camera (SensiCam, PCO imaging, Kelheim, Germany) at sampling frequency set to $2 \mathrm{fps}$. Cells were further characterized by their responsiveness to a brief application of high potassium $(50 \mathrm{mM} \mathrm{KCl}$ with compensated osmolarity) as a marker for neurons.

\section{Statistical Analysis}

Nociceptive firing was statistically analyzed using OriginPro 9.1 software (Microcal, Northampton, MA, USA) and SigmaPlot 11.0 (Systat Software Inc., CA, USA). One-way repeated measures ANOVA with Tukey post hoc test was used. Mast cell degranulation data were analyzed using two-tailed Mann-Whitney $U$ test with GraphPad Prism software (La Jolla, CA, USA). Two-tailed Student's $t$-test [OriginPro 9.1 software (Microcal, Northampton, MA, USA)] was applied to evaluate the significance of increase in basal meningeal firing after $1 \mu \mathrm{M}$ CGRP pre-application. Results are expressed as mean of data \pm SE unless otherwise stated. In all tests, $p<0.05$ was taken as significant.

\section{RESULTS}

\section{Nociceptive Firing Induced by Carbachol}

To study if cholinergic agents can stimulate or inhibit meningeal nociceptive signaling, we applied various AChR agonists directly to the rat hemiskull preparation with preserved dura mater innervation. To this end, we recorded spontaneous nociceptive firing of meningeal trigeminal nerves in basal conditions, then the preparation was superfused with a ligand solution, and changes in spike frequency were monitored.

First, we applied the natural agonist ACh to rat hemiskull preparation. Application of $250 \mu \mathrm{M}$ ACh significantly increased nociceptive firing (Figures 1A-C). Figures 1A,B show representative spikes in control and after ACh application, respectively. Notice that the amplitude and the shape of spikes were not significantly changed after ACh treatment (Figures 1A,B, inset). On average, the frequency of spikes was increased by 2.5 -fold by $10 \mathrm{~min}$ of $250 \mu \mathrm{M}$ ACh application $(n=6, p<0.05$, Figure 1C). Lower $(50 \mu \mathrm{M})$ concentration of ACh slightly increased spike frequency, but this effect was not significant $(n=6, p>0.05$, Figure 1C).

Because ACh, an endogenous agonist of both mAChRs and nAChRs, quickly degrades in live tissues, we next used the stable agonist carbachol, to test whether it can induce similar or higher level of firing. Although ACh demonstrates comparable activity towards both classes of AChRs, carbachol is more potent to $\mathrm{mAChR}$, to which it demonstrates nanomolar affinity in contrast 
A

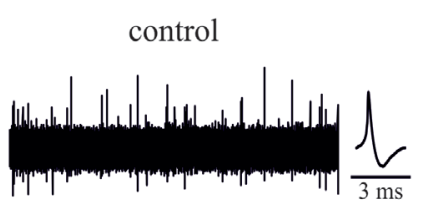

C

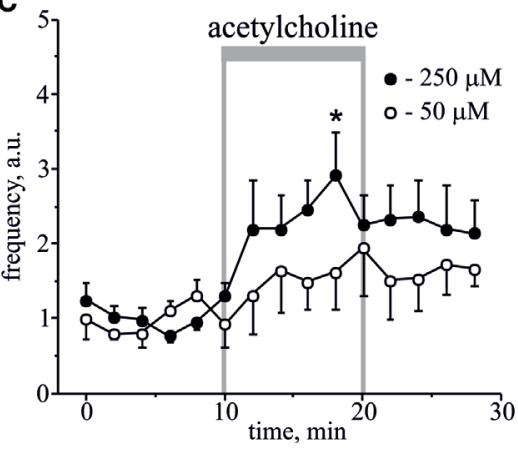

B

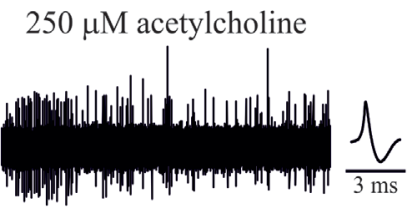

D

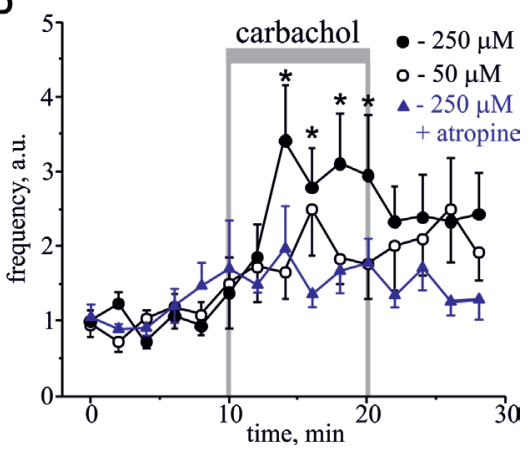

FIGURE 1 | Action of acetylcholine (ACh) and carbachol on nociceptive firing in the meningeal trigeminal nerves. (A) Representative traces of trigeminal nociceptive firing and average spike shape in control conditions and (B) during application of $250 \mu \mathrm{M}$ ACh. (C) The time-course of changes of nociceptive spike frequency during application of 50 and $250 \mu \mathrm{M}$ ACh. (D) The time-course of changes of nociceptive spike frequency during application of 50 and $250 \mu \mathrm{M}$ carbachol and $250 \mu \mathrm{M}$ carbachol in the presence of $1 \mu \mathrm{M}$ atropine. Each time point represents a mean spike frequency for 2 min of recording (mean \pm SEM, $n=6-10$, one-way repeated measures ANOVA, Tukey test, $\left.{ }^{*} p<0.05\right)$

to micromolar constants for its binding to nAChRs (29-32). Like low doses of $\mathrm{ACh}, 50 \mu \mathrm{M}$ carbachol showed a clear tendency to increase firing, but this effect was not significant $(n=10, p>0.05$, Figure 1D). However, application of $250 \mu \mathrm{M}$ carbachol to the rat hemiskull preparation significantly increased the number of nociceptive spikes peaking by 5-10 min of drug application ( $n=6, p<0.05$, Figure 1D). Moreover, the significantly increased number of spikes was detected even 6 min after carbachol withdrawal. Notice that the same concentration of ACh induced the significant changes in firing only after $10 \mathrm{~min}$ of the compound application consistent with higher pro-nociceptive efficacy of carbachol.

The pro-nociceptive action of carbachol was largely reduced by pretreatment with broad spectrum muscarinic antagonist, atropine. Thus, in the presence of $1 \mu \mathrm{M}$ atropine, $250 \mu \mathrm{M}$ carbachol only slightly increased nociceptive firing, but this effect was non-significant $(n=7, p>0.05$, Figure 1D).

\section{Involvement of Nicotinic Receptors in Nociceptive Firing}

Essential evidence suggests that ligand-gated nicotinic receptors (nAChRs) are also expressed by nociceptive sensory neurons to modulate the nociceptive signaling (33-37). During carbachol application, the role of nAChRs could be masked by simultaneous activation of multiple $\mathrm{mAChRs}$ often producing functionally opposite effects on nociceptive neurotransmission (38-40). Therefore, to investigate directly a contribution of nAChRs to the nociceptive signaling in meninges, we used the specific nAChRs agonist nicotine. Nicotine $(100 \mu \mathrm{M})$ induced a strong and prolonged nociceptive firing in trigeminal nerves (Figure 2A). This effect was peaking at $8-10 \min (n=8, p<0.05$, Figure 2B) of nicotine application. Consistent with the involvement of nAChRs, pre-application of $50 \mu \mathrm{M}$ D-tubocurarine completely prevented the pro-nociceptive effect of nicotine ( $n=9, p>0.05$, Figure 2C). TRPA1 receptors have also been suggested as molecular targets sensitive to this agonist $(18,19)$. However, in rat meninges, TRPA1 receptors are unlikely the target for nicotine, as the selective TRPA1 blocker $25 \mu \mathrm{M}$ HC-030031 did not prevent the pronociceptive action of nicotine $(n=7$, Figure $2 \mathrm{D})$.

\section{AChE, BuChE, and the Role of Endogenous ACh}

To study a role of endogenous meningeal cholinergic system in rat dura mater, we explored the expression and localization of $\mathrm{AChE}$ and BuChE, two key enzymes implicated in cholinergic signaling by termination of ACh action. The cholinesterasepositive nerve fibers were found mainly in perivascular regions ( $n=7$ hemiskulls), although spare labeling was observed across the dura mater. Figures $\mathbf{3 A}-\mathbf{F}$ present a co-expression of $\mathrm{AChE}$ and $\mathrm{BuChE}$ with neurofilaments (NF-H) in nerve fibers located nearby meningeal blood vessels. Such localization of both enzymes in dura mater suggests their role in control of AChmediated signaling.

Further, to test the involvement of endogenous ACh in regulation of meningeal nociceptive firing, we applied the classical inhibitor of AChE neostigmine to the hemiskull preparation, to increase the concentration of endogenous ACh around nerve fibers. Neostigmine $(12.5 \mu \mathrm{M})$ did not change the nociceptive firing per se $(n=5, p>0.05$, Figures 4A,B). However, a significant neostigmine-induced increase in nociceptive firing was observed after $2 \mathrm{~h}$ exposure of meninges to the migraine mediator calcitonin gene-related peptide (CGRP, $1 \mu \mathrm{M})$. Thus, in this case, the 
A

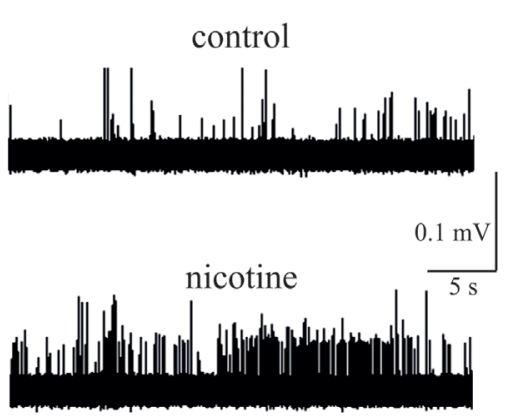

C

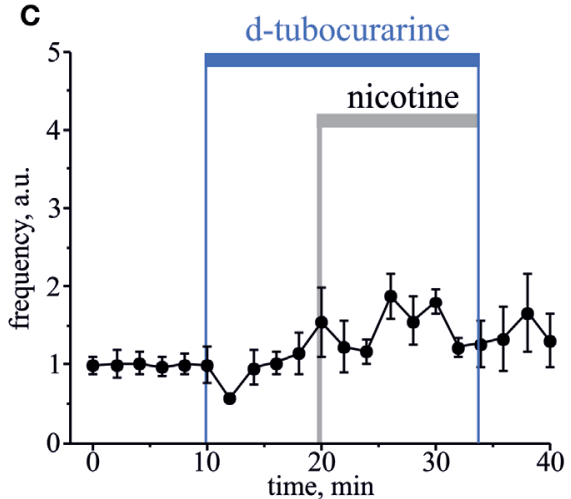

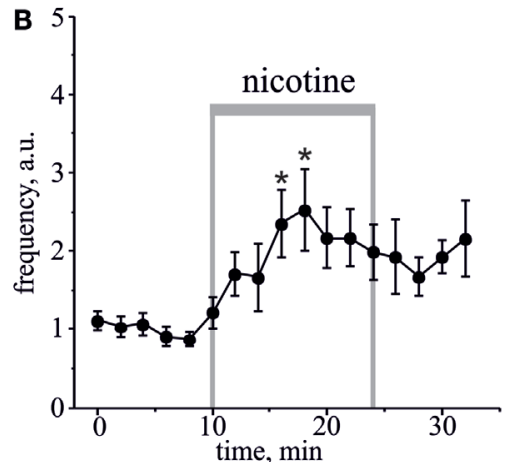

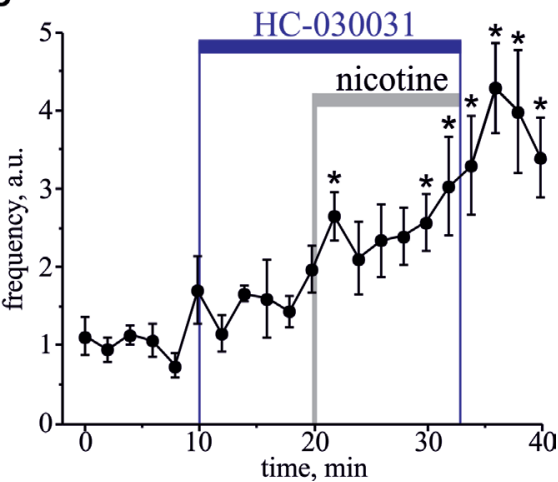

FIGURE 2 Action of nicotine on nociceptive firing in the meningeal trigeminal nerves. (A) Representative traces of trigeminal nociceptive spikes in control conditions and during application of $100 \mu \mathrm{M}$ nicotine. (B) The time-course of changes of nociceptive spike frequency during application of $100 \mu \mathrm{M}$ nicotine. (C) The time-course of changes of nociceptive spike frequency during application of $100 \mu \mathrm{M}$ nicotine in the presence of $50 \mu \mathrm{M} D$-tubocurarine and (D) in the presence of $25 \mu \mathrm{M} \mathrm{HC}-030031$. Notice that D-tubocurarine (a non-selective nicotinic antagonist) prevented this effect, but HC-030031 (a specific TRPA1 blocker) did not prevent the pro-nociceptive action of nicotine. Each time point represents a mean spike frequency for 2 min (mean \pm SEM, $n=7-9$, one-way repeated measures ANOVA, Tukey test, $\left.{ }^{*} p<0.05\right)$
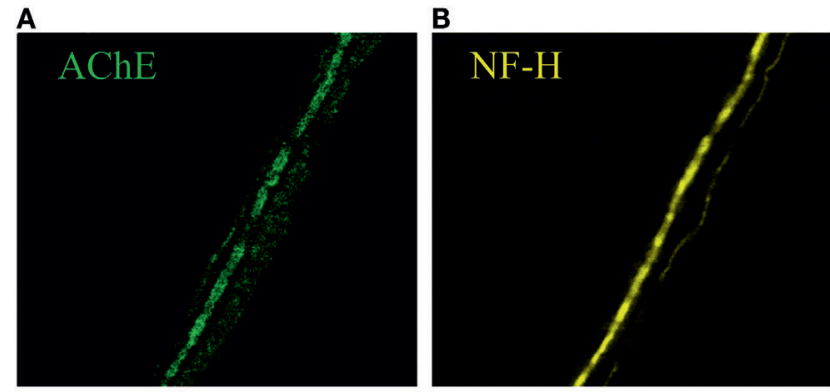

D

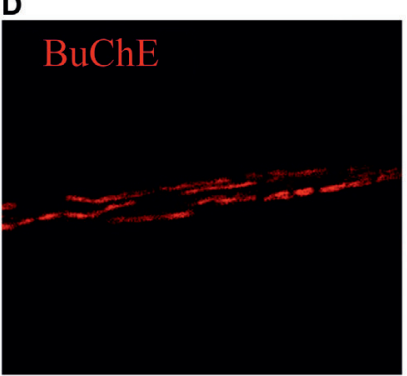

E

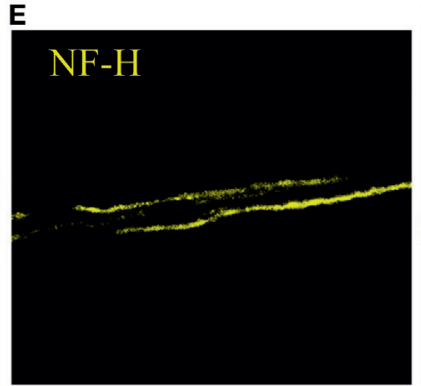

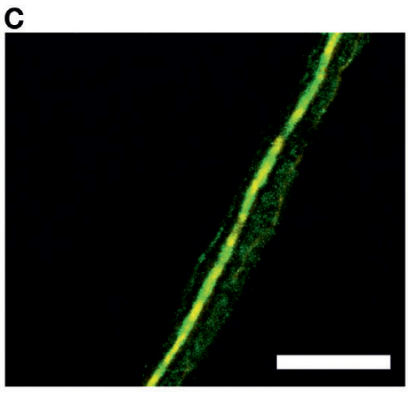

F

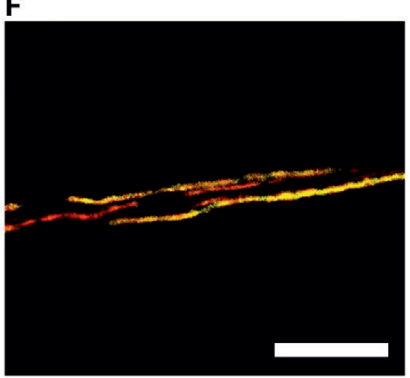

FIGURE 3 | Immunohistochemical staining of (A) acetylcholinesterase (AChE, green), (D) butyrylcholinesterase (BuChE, red) and (B,E) neurofilaments (NF-H, neurofilaments heavy chain, yellow) in perivascular nerve fibers in rat dura mater preparation. Co-localization with neurofilaments, markers of myelinated axons, is shown in (C) and (F). Scale bar, $40 \mu \mathrm{m}$. 

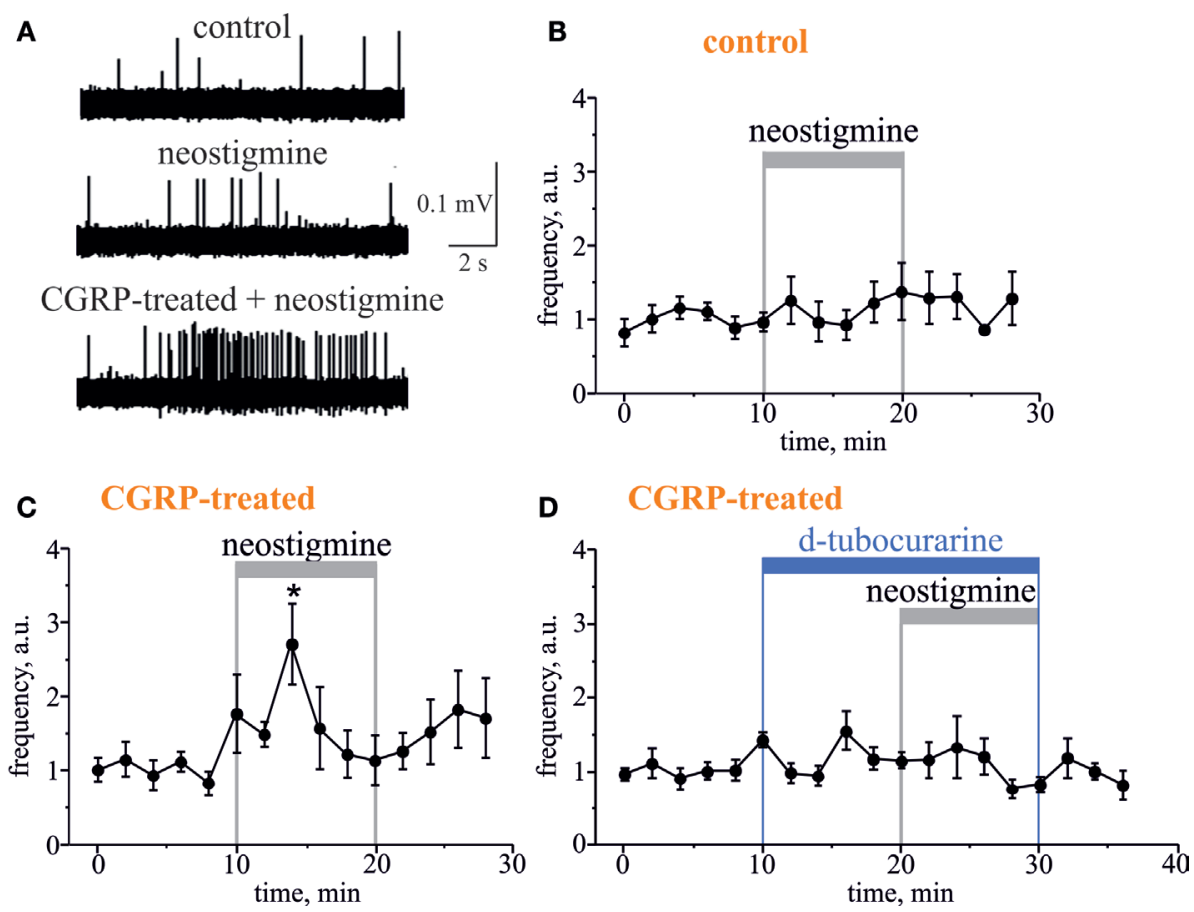

FIGURE 4 | Pro-nociceptive action of neostigmine in CGRP-sensitized hemiskull preparation. (A) Representative traces of trigeminal nociceptive firing in control conditions, during $12.5 \mu \mathrm{M}$ neostigmine application and neostigmine application in $1 \mu \mathrm{M}$ CGRP-pretreated preparation. (B) The time-course of changes of nociceptive spike frequencies after application of $12.5 \mu \mathrm{M}$ neostigmine in a control and (C) in CGRP-sensitized hemiskull (preincubation in $1 \mu \mathrm{M}$ CGRP for $2 \mathrm{~h}$ ). (D) The time-course of changes of nociceptive spike frequency in CGRP-sensitized hemiskull after application of $12.5 \mu \mathrm{M}$ neostigmine in the presence of $50 \mu \mathrm{M}$ D-tubocurarine. Notice that application of a non-selective nicotinic antagonist D-tubocurarine prevented nociceptive firing induced by neostigmine. Each plot point represents a mean spike frequency for 2 min (mean \pm SEM, $n=5-7$, one-way repeated measures ANOVA, Tukey test, ${ }^{*} p<0.05$ ).

number of spikes was increased by 6 min action of neostigmine by 2.7 -fold ( $n=7, p<0.05$, Figures $4 \mathrm{~A}, \mathrm{C}$ ). The basal level of trigeminal firing was not changed after $2 \mathrm{~h}$ preincubation with $1 \mu \mathrm{M}$ CGRP (372 \pm 124 spikes in 10 min recording, $n=12$ ) versus $385 \pm 75$ spikes in control $(n=12, p>0.05)$. Importantly, co-application of $50 \mu \mathrm{M}$ D-tubocurarine (non-selective nAChR antagonist) prevented the facilitatory pro-nociceptive action of neostigmine $(n=5, p<0.05$, Figure 4D), suggesting the major role of nicotinic AChRs in mechanism of neostigmineinduced firing.

\section{Carbachol but Not Nicotine Degranulates Dural Mast Cell}

As degranulation of mast cells has been recently suggested as one of potential triggers of migraine $(22,41)$, we next tested the ability of carbachol and nicotine to induce degranulation of dural mast cells. In these experiments, we also explored a possible role of gender in the ability of these cholinergic agents to induce degranulation. Figure 5 shows representative samples of mast cells in control (Figure 5A) and after application of $50 \mu \mathrm{M}$ carbachol (Figure 5B). Pooled data in Figure 5C show that the application of $50 \mu \mathrm{M}$ carbachol to the whole mount meningeal preparation for 20 min induced a significant degranulation of mast cells in both sexes. Thus, in males, the level of degranulation in control (vehicle treatment) was $10 \pm 8 \%(n=4)$, whereas it was largely enhanced up to $62 \pm 5 \%$ after $50 \mu \mathrm{M}$ carbachol treatment $(n=4, p<0.05)$. In females, there was $19 \pm 5 \%$ of degranulation in control $(n=4)$, and the large enhancement of degranulation up to $61 \pm 8 \%$ was observed after $50 \mu \mathrm{M}$ carbachol exposure $(n=4$, $p<0.05)$.

In contrast to carbachol, the concentrations of nicotine, which induced the nociceptive firing, did not promote degranulation of mast cells (Figure 5D) suggesting only a direct action of this agonist on nerve terminals. Thus, in males, the level of mast cells degranulation was $22 \pm 4 \%$ in control $(n=4)$ and $20 \pm 4 \%$ after application of $100 \mu \mathrm{M}$ nicotine $(n=4, p>0.05)$. Likewise, in females, these values were $24 \pm 8 \%$ for vehicle $(n=4)$ and $24 \pm 5 \%$ for nicotine treatment $(n=4, p>0.05)$.

Thus, the pro-nociceptive action of nicotine was clearly mast cells independent, whereas the action of carbachol could potentially be, at least partly, mediated by products released from degranulated mast cells.

\section{Calcium Transients Induced by Nicotine in Trigeminal Neurons}

The somas of TG neurons are important components of peripheral trigeminal nociceptive system, and they could be implicated in development of migraine pain (1). To study the effect of cholinergic agents in this part of the trigeminal nociceptive system, we used the live imaging technique to monitor $\mathrm{Ca}^{2+}$ signals in 

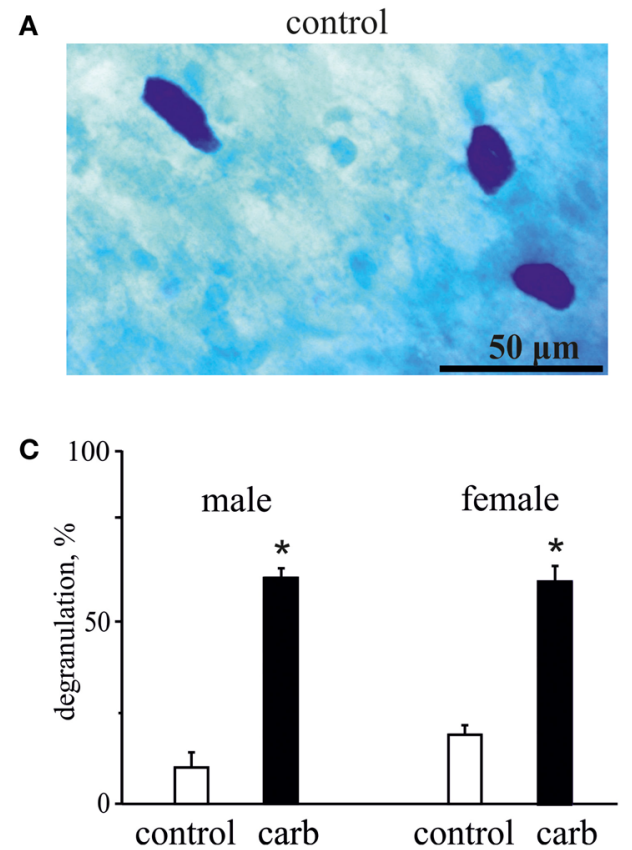
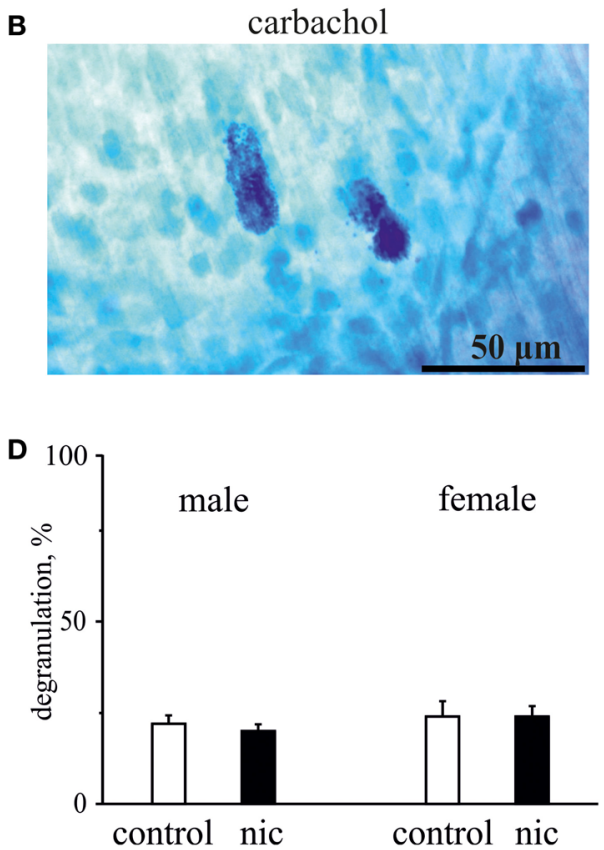

FIGURE 5 | Action of carbachol and nicotine on degranulation of mast cells. (A) Example of intact well-shaped mast cells in control. (B) Example of degranulated mast cells (notice distorted borders) in the presence of $50 \mu \mathrm{M}$ carbachol. (C) Histograms showing the effect of $50 \mu \mathrm{M}$ carbachol on degranulation of mast cells obtained from male and female rats. (D) Histograms showing the effect of $100 \mu \mathrm{M}$ nicotine on degranulation of mast cells obtained from male and female rats. Notice lack of nicotine effect on mast cell degranulation. Mean $\pm \mathrm{SD}, n=4$, Mann-Whitney $U$ test, ${ }^{\star} p<0.05$.

neurons isolated from TG. Application of $50 \mathrm{mM} \mathrm{KCl}$ at the end of protocol was used to identify neurons (42). To study the neurochemical profile of the neurons responding to cholinergic agonists, we tested if they were activated by the classical algogen capsaicin operating via TRPV1 receptors (43). We found a variable profile of trigeminal neurons as some cells responded to nicotine, some only to capsaicin and the fraction of cells responded to both agonists.

Figure 6 shows example of two neurons exposed to $100 \mu \mathrm{M}$ nicotine. In one trigeminal neuron (Figure 6A), nicotine induced a large fast $\mathrm{Ca}^{2+}$ transient, and later this neuron responded also to capsaicin. In the other neuron (Figure 6B), nicotine apparently did not evoke response; however, this cell also responded to capsaicin suggesting the nociceptive phenotype. On average, almost half of neurons (43\%, 70/163 cells) responded to nicotine suggesting that $\mathrm{nAChRs}$ can have an important role in trigeminal nociception. Consistent with previous data, 34\% of neurons (56/163) were sensitive to application of $200 \mathrm{nM}$ capsaicin. Part of them (12/56 cells) were also sensitive to nicotine.

We also tested the action of carbachol to address the presence of $\mathrm{mAChRs}$ and their co-expression with nicotinic receptors in individual trigeminal neurons (Figure 7). For this purpose we first applied $100 \mu \mathrm{M}$ nicotine with subsequent application of $50 \mu \mathrm{M}$ carbachol. We found that $71 \%$ of neurons (82/116) responded to carbachol, whereas $70 \%$ of these cells were responsive also to nicotine application. Thus, there were neurons that responded only to carbachol application (Figure 7B) suggesting functional expression of $\mathrm{mAChRs}$ in trigeminal neurons.

\section{A neuron 1}
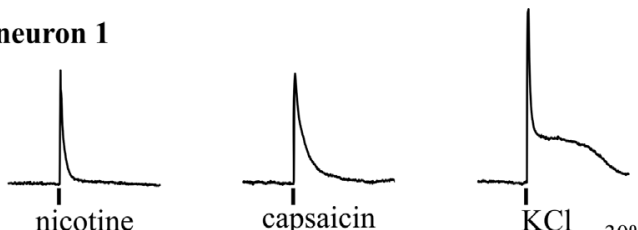

B
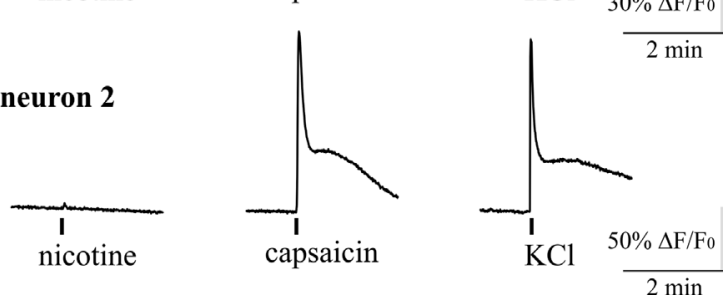

FIGURE 6 | Intracellular $\mathrm{Ca}^{2+}$ responses induced by nicotine and capsaicin in trigeminal neurons. (A) Example of intracellular calcium transient induced by $100 \mu \mathrm{M}$ nicotine in TRPV1-positive neuron (sensitive to 200 nM capsaicin). (B) Example of calcium transient activated by 200 nM capsaicin in nicotine-negative neuron. All agonists were applied for $2 \mathrm{~s}$ with at least 2-min intervals between applications. Application of $50 \mathrm{mM} \mathrm{KCl}$ was used as a marker for identification of neurons. Statistical analysis of these experiments is given in the Section "Results."

\section{DISCUSSION}

In this study, we provide for a first time a detailed analysis of cholinergic regulation of nociception in meninges, which is supposed to be an origin site for migraine pain. Activation of firing 


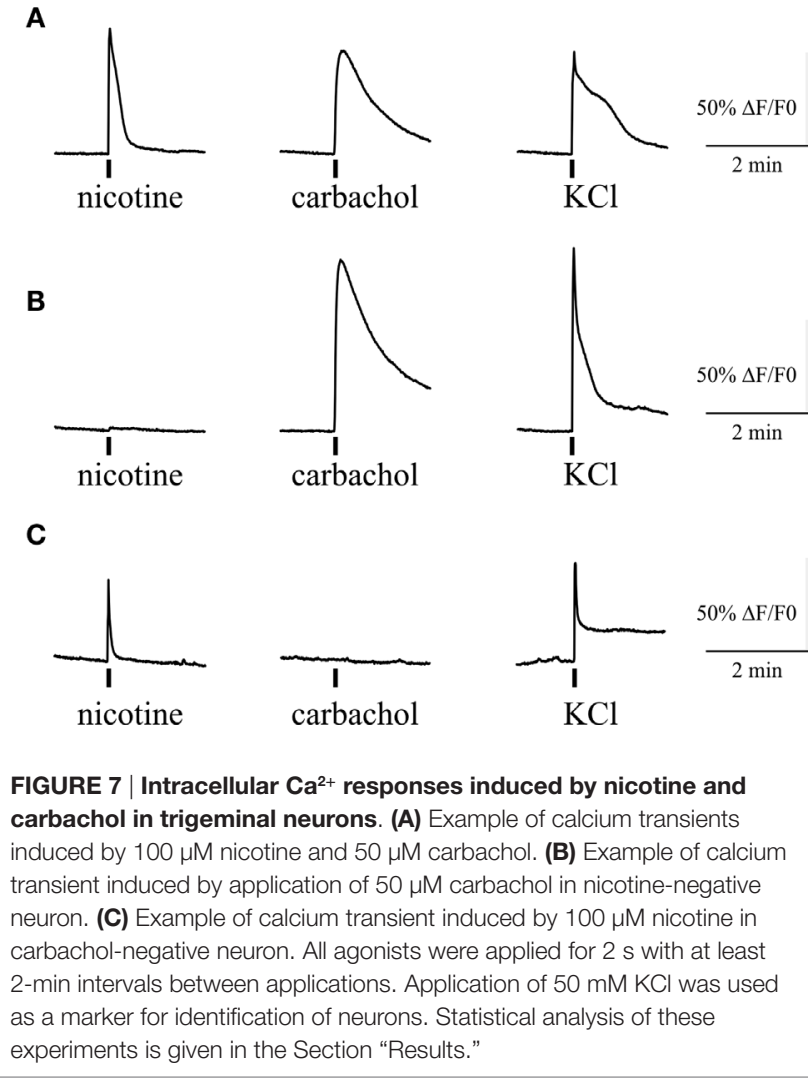

in trigeminal nerve terminals was induced by the natural agonist $\mathrm{ACh}$ and its stable analog carbachol. The action of carbachol was prevented by atropine suggesting presence of muscarinic receptors. Similar size effect was induced by nicotine indicating also expression of nicotinic receptors in the nociceptive fibers. Our data are consistent with view that trigeminal nerve fibers represent a target for the pro-nociceptive action of ACh released from parasympathetic fibers innervating meninges. The pro-nociceptive role of endogenous ACh was detected in a CGRP-sensitized meningeal preparation. Consistent with data in meninges, isolated trigeminal neurons also responded to nicotine and carbachol by generation of $\mathrm{Ca}^{2+}$ transients. In contrast to nerve endings, residual mast cells did not respond to nicotine but readily degranulated their content to application of carbachol. These data provide a mechanistic interpretation for parasympathetic innervation of meninges and explain such phenomena as carbachol-induced headache in humans.

The physiologically important interaction between parasympathetic and trigeminal sensory systems in meninges has been suggested earlier (5-8). However, the fact of ACh action on trigeminal nerve terminals and molecular mechanisms underlying these processes remained unknown to date. Therefore, our primary aim was to shed a light on the molecular mechanisms of communication between parasympathetic and nociceptive trigeminal signaling. Both two main type of cholinesterases (AChE and BuChE), known to be involved in the metabolism of $\mathrm{ACh}$, we found in perivascular neurofilament-rich nerve fibers around big meningeal vessels. The presence of neurofilaments (44) indicated that most of $\mathrm{AChE}$ - and BuChE-positive axons were myelinated. The previously obtained data (45) suggested that such nerve fibers could be parasympathetic in nature. Although a very weak enzymatic activity of AChE was also discovered in axons diffusely spread in the meningeal tissue (45), the perivascular nerve fibers are primarily implicated in ACh signaling in meninges.

Inhibition of cholinesterase activity, which is associated with increased level of endogenous ACh, intensified the nociceptive trigeminal firing in CGRP-sensitized dura mater. Thus, in experimental migraine-like conditions induced by CGRP (46), endogenous ACh is able to produce the pro-nociceptive effect, which supports the pathophysiological role of such type of signaling. This effect is mainly mediated through nAChRs, since the nicotinic agonist D-tubocurarine was able to prevent the action of neostigmine, a cholinesterase inhibitor.

Our data suggest that in dura mater, sensory afferent nerve endings are expected to be the target for the excitatory action of nicotine. This is consistent with data from other tissues, such as skin or nasal epithelium, where nicotine can directly activate nociceptive nerve endings (36, 47-50).

Somas of trigeminal neurons are the most common model of trigeminal nerve endings. Our results obtained in isolated trigeminal neurons were in agreement with data from hemiskull preparation. Indeed, we found a strong enhancement of intracellular calcium concentration in trigeminal neurons in response to nicotine in about half of trigeminal neurons. Moreover, in cultures that are lacking mast cells, essential fraction of neurons was also activated by carbachol consistent with presence of mAChRs in trigeminal afferents.

Nicotinic AChRs presented in sensory neurons have diverse subunit composition (51). All neuronal nAChR subunits were detected at mRNA level in trigeminal and dorsal root ganglion neurons, but $\alpha 7, \alpha 3 \beta 4$, and $\alpha 6 \beta 4$ nAChRs appeared to be the main functionally active receptor subtypes in sensory neurons $(33,35,52-55)$. Metabotropic $\mathrm{mAChRs}$ are likely presented on cell bodies and nerve endings of primary afferents, and the functional expression of M2, M3 and M4 subtypes was reported earlier $(40,49,56,57)$. However, in contrast to nAChRs producing mainly the excitatory effect on sensory neurotransmission $(37,47)$, activation of mAChRs in primary afferents can also inhibit the nociceptive activity on the periphery $(5,40,49)$ and in the spinal cord (58). The functional outcome, therefore, depends on density and mAChR subtypes expressed in trigeminal nerve endings. Thus, the role of $\mathrm{mAChR}$ subtypes in trigeminal neurons innervating dura mater deserves the special investigation with specific ligands for multiple types of mAChRs.

In contrast to nicotine, carbachol provoked a massive degranulation of a significant portion of meningeal mast cells. These immune cells are localized in close proximity to dural nociceptive nerve fibers $(21,59)$ and are able to secrete numerous pronociceptive mediators $(21,59-62)$. Degranulation of dural mast cells can lead to persistent activation of dural nociceptors (41) and the headache pain pathway $(22,63)$. Interestingly, according to some reports, mast cells degranulation is modulated by sex hormones in a gender-selective fashion, with mast cells from females being more susceptible than mast cells in males (64). However, 


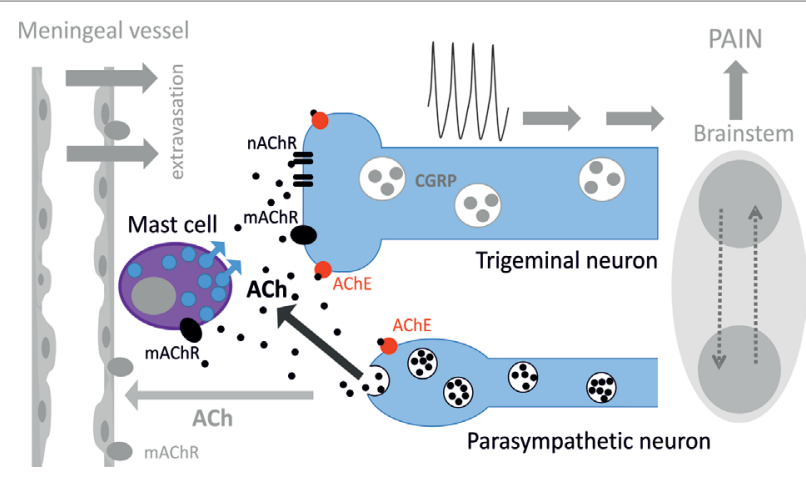

FIGURE 8 | Schematic representation of cholinergic signaling in peripheral nociception in meninges. Meninges have a dual innervation by somatic trigeminal nerves and postganglionic parasympathetic nerve fibers. Acetylcholine $(\mathrm{ACh})$ released from parasympathetic nerves can activate mast cells via muscarinic $A C h$ receptor (mAChR) and trigeminal nerve endings both via mAChR and nicotinic ACh receptor ( $\mathrm{AAChR}$ ). This concerted activation of ACh receptors (AChRs) results in generation of the nociceptive firing in primary afferents. The lifespan of ACh is limited by activity of acetylcholinesterase (AChE), which destroys this neurotransmitter. Potentially, ACh can also approach small meningeal vessels producing vasodilation and plasma protein extravasation most likely via mAChRs (8). At the level of the brainstem, these two systems can interact via the trigemino-parasympathetic reflex leading to sustained neuronal activity. The outcome of cholinergic activation in meninges is the release of pro-inflammatory transmitters and cytokines from mast cells, extravasation, excitation, and sensitization of nociceptive afferents resulting in trigeminal pain.

we did not observe any sex-dependent difference in cholinergic activation of dural mast cell degranulation for male and female rats, probably due to young age of these animals. Nevertheless, our data suggest that in rat dura mater carbachol might indirectly activate nociceptors provoking mast cells degranulation through mAChRs.

Figure 8 provides a schematic presentation of results obtained in this study along with some previous key observations on the role of parasympathetic nerves in meninges. Thus, postganglionic parasympathetic nerve fibers can release ACh degranulating dural mast cells mainly via mAChRs. Degranulation of mast cells is associated with release of multiple pro-inflammatory transmitters and cytokines supporting neuroinflammation in meninges. Our recent study indicated the key role of serotonin derived from degranulated mast cells in activation of trigeminal nerve terminals (41). ACh can even directly activate trigeminal nerve endings both via mAChRs and $\mathrm{nAChRs} \mathrm{providing} \mathrm{essential} \mathrm{noci-}$ ceptive firing in primary afferents. The main migraine mediator neuropeptide CGRP could be released from peptidergic nerve terminals and be involved in facilitation of cholinergic signaling. This could be either via enhanced ACh release, as CGRP can

\section{REFERENCES}

1. Messlinger K. Migraine: where and how does the pain originate? Exp Brain Res (2009) 196(1):179-93. doi:10.1007/s00221-009-1756-y

2. Zhang Y, Zhao S, Rodriguez E, Takatoh J, Han BX, Zhou X, et al. Identifying local and descending inputs for primary sensory neurons. J Clin Invest (2015) 125(10):3782-94. doi:10.1172/JCI81156 induce $\mathrm{Ca}^{2+}$ transients in certain cell types including neurons $(65,66)$, or via facilitation of ACh signaling due to CGRP-induced membrane traffic of cholinergic receptors, similar to ATP-gated P2X3 receptors (67). Thus, a complex activity of CGRP could be implicated in its modulatory action in meninges, and this issue deserves further studies.

Like in other tissues, ACh signaling depends on availability and activity of AChE and BuChE, which both present in meninges. Previous studies revealed that ACh released during stimulation of the SPG can induce vasodilation and plasma protein extravasation in dura mater via mAChRs (8). All these mechanisms should largely intensify the nociceptive traffic to the brainstem to promote headache and support the trigemino-parasympathetic reflex (6).

\section{CONCLUSION}

The pro-nociceptive cholinergic effects observed in the current study likely involve several molecular targets such as nAChRs and $\mathrm{mAChRs}$ in trigeminal nociceptive neurons and mAChRs in mast cells provoking release of pro-inflammatory agents. Thus, ACh derived from parasympathetic nerve fibers could be implicated in trigeminal pain and, probably, contribute to induction of headache in conditions favoring the release of this key neurotransmitter of the autonomous nervous system.

\section{ETHICS STATEMENT}

All experimental procedures were performed in accordance with the European Community Council Directive of September 22, 2010 (2010/63/EEC), and the experimental protocol was approved by the Animal Care and Use Committee of the University of Eastern Finland (license EKS-004-2014). All efforts were made to minimize the number of animals used and their suffering.

\section{AUTHOR CONTRIBUTIONS}

Design of the study: IS, EN, and RG. Conducting the study and analysis: IS, NM, PA, and LN. Manuscript preparation: IS, NM, and RG.

\section{FUNDING}

The study was supported by the Finnish Academy (grant 277442), the program of competitive growth of Kazan Federal University and the subsidy allocated to Kazan Federal University for the state assignment in the sphere of scientific activities. IS was supported by Russian Science Foundation (grant 16-14-00215).

3. Goadsby PJ, Charbit AR, Andreou AP, Akerman S, Holland PR. Neurobiology of migraine. Neuroscience (2009) 161(2):327-41. doi:10.1016/j. neuroscience.2009.03.019

4. Andreou AP, Holland PR, Lasalandra MP, Goadsby PJ. Modulation of nociceptive dural input to the trigeminocervical complex through GluK1 kainate receptors. Pain (2015) 156(3):439-50. doi:10.1097/01.j.pain.0000460325. 25762.c0 
5. Ebersberger A, Takac H, Richter F, Schaible HG. Effect of sympathetic and parasympathetic mediators on the release of calcitonin gene-related peptide and prostaglandin E from rat dura mater, in vitro. Cephalalgia (2006) 26(3):282-9. doi:10.1111/j.1468-2982.2005.01035.x

6. Bolay H, Reuter U, Dunn AK, Huang Z, Boas DA, Moskowitz MA. Intrinsic brain activity triggers trigeminal meningeal afferents in a migraine model. Nat Med (2002) 8(2):136-42. doi:10.1038/nm0202-136

7. Yarnitsky D, Goor-Aryeh I, Bajwa ZH, Ransil BI, Cutrer FM, Sottile A, et al. 2003 Wolff Award: possible parasympathetic contributions to peripheral and central sensitization during migraine. Headache (2003) 43(7):704-14. doi:10.1046/j.1526-4610.2003.03127.x

8. Delepine L, Aubineau P. Plasma protein extravasation induced in the rat dura mater by stimulation of the parasympathetic sphenopalatine ganglion. Exp Neurol (1997) 147(2):389-400. doi:10.1006/exnr.1997.6614

9. Cady R, Saper J, Dexter K, Manley HR. A double-blind, placebo-controlled study of repetitive transnasal sphenopalatine ganglion blockade with tx360((R)) as acute treatment for chronic migraine. Headache (2015) 55(1): 101-16. doi:10.1111/head.12458

10. Schytz HW, Wienecke T, Olesen J, Ashina M. Carbachol induces headache, but not migraine-like attacks, in patients with migraine without aura. Cephalalgia (2010) 30(3):337-45. doi:10.1111/j.1468-2982.2009.01929.x

11. Grande G, Nilsson E, Edvinsson L. Comparison of responses to vasoactive drugs in human and rat cerebral arteries using myography and pressurized cerebral artery method. Cephalalgia (2013) 33(3):152-9. doi:10.1177/ 0333102412468340

12. Mangione AS, Obara I, Maiaru M, Geranton SM, Tassorelli C, Ferrari E, et al. Nonparalytic botulinum molecules for the control of pain. Pain (2016) 157(5):1045-55. doi:10.1097/j.pain.0000000000000478

13. Le H, Tfelt-Hansen P, Skytthe A, Kyvik KO, Olesen J. Association between migraine, lifestyle and socioeconomic factors: a population-based cross-sectional study. J Headache Pain (2011) 12(2):157-72. doi:10.1007/ s10194-011-0321-9

14. Dineley KT, Pandya AA, Yakel JL. Nicotinic ACh receptors as therapeutic targets in CNS disorders. Trends Pharmacol Sci (2015) 36(2):96-108. doi:10.1016/ j.tips.2014.12.002

15. Marubio LM, del Mar Arroyo-Jimenez M, Cordero-Erausquin M, Lena C, Le Novere N, de Kerchove d'Exaerde A, et al. Reduced antinociception in mice lacking neuronal nicotinic receptor subunits. Nature (1999) 398(6730):805-10. doi:10.1038/19756

16. Yamamoto A, Kiguchi N, Kobayashi Y, Maeda T, Ueno K, Yamamoto C, et al. Pharmacological relationship between nicotinic and opioid systems in analgesia and corticosterone elevation. Life Sci (2011) 89(25-26):956-61. doi:10.1016/j.lfs.2011.10.004

17. Tripathi HL, Martin BR, Aceto MD. Nicotine-induced antinociception in rats and mice: correlation with nicotine brain levels. J Pharmacol Exp Ther (1982) 221(1):91-6.

18. Talavera K, Gees M, Karashima Y, Meseguer VM, Vanoirbeek JA, Damann N, et al. Nicotine activates the chemosensory cation channel TRPA1. Nat Neurosci (2009) 12(10):1293-9. doi:10.1038/nn.2379

19. Schreiner BS, Lehmann R, Thiel U, Ziemba PM, Beltran LR, Sherkheli MA, et al. Direct action and modulating effect of (+)- and (-)-nicotine on ion channels expressed in trigeminal sensory neurons. Eur J Pharmacol (2014) 728:48-58. doi:10.1016/j.ejphar.2014.01.060

20. Olesen J, Burstein R, Ashina M, Tfelt-Hansen P. Origin of pain in migraine: evidence for peripheral sensitisation. Lancet Neurol (2009) 8(7):679-90. doi:10.1016/S1474-4422(09)70090-0

21. Rozniecki JJ, Dimitriadou V, Lambracht-Hall M, Pang X, Theoharides TC. Morphological and functional demonstration of rat dura mater mast cell-neuron interactions in vitro and in vivo. Brain Res (1999) 849(1-2):1-15. doi:10.1016/S0006-8993(99)01855-7

22. Levy D, Burstein R, Kainz V, Jakubowski M, Strassman AM. Mast cell degranulation activates a pain pathway underlying migraine headache. Pain (2007) 130(1-2):166-76. doi:10.1016/j.pain.2007.03.012

23. Shatillo A, Koroleva K, Giniatullina R, Naumenko N, Slastnikova AA, Aliev RR, et al. Cortical spreading depression induces oxidative stress in the trigeminal nociceptive system. Neuroscience (2013) 253:341-9. doi:10.1016/j. neuroscience.2013.09.002

24. Schwenger N, Dux M, de Col R, Carr R, Messlinger K. Interaction of calcitonin gene-related peptide, nitric oxide and histamine release in neurogenic blood flow and afferent activation in the rat cranial dura mater. Cephalalgia (2007) 27(6):481-91. doi:10.1111/j.1468-2982.2007.01321.x

25. Schueler M, Messlinger K, Dux M, Neuhuber WL, De Col R. Extracranial projections of meningeal afferents and their impact on meningeal nociception and headache. Pain (2013) 154(9):1622-31. doi:10.1016/j.pain.2013.04.040

26. Pedersen SH, Ramachandran R, Amrutkar DV, Petersen S, Olesen J, Jansen-Olesen I. Mechanisms of glyceryl trinitrate provoked mast cell degranulation. Cephalalgia (2015) 35(14):1287-97. doi:10.1177/0333102415574846

27. Boes T, Levy D. Influence of sex, estrous cycle, and estrogen on intracranial dural mast cells. Cephalalgia (2012) 32(12):924-31. doi:10.1177/0333102412454947

28. Malin SA, Davis BM, Molliver DC. Production of dissociated sensory neuron cultures and considerations for their use in studying neuronal function and plasticity. Nat Protoc (2007) 2(1):152-60. doi:10.1038/nprot.2006.461

29. Parker MJ, Beck A, Luetje CW. Neuronal nicotinic receptor beta 2 and beta 4 subunits confer large differences in agonist binding affinity. Mol Pharmacol (1998) 54(6):1132-9.

30. Bolchi C, Valoti E, Binda M, Fasoli F, Ferrara R, Fumagalli L, et al. Design, synthesis and binding affinity of acetylcholine carbamoyl analogues. Bioorg Med Chem Lett (2013) 23(23):6481-5. doi:10.1016/j.bmcl.2013.09.023

31. Garcia RC, Dati LM, Torres LH, da Silva MA, Udo MS, Abdalla FM, et al. M1 and M3 muscarinic receptors may play a role in the neurotoxicity of anhydroecgonine methyl ester, a cocaine pyrolysis product. Sci Rep (2015) 5:17555. doi:10.1038/srep17555

32. Xiao Y, Meyer EL, Thompson JM, Surin A, Wroblewski J, Kellar KJ. Rat alpha3/ beta4 subtype of neuronal nicotinic acetylcholine receptor stably expressed in a transfected cell line: pharmacology of ligand binding and function. Mol Pharmacol (1998) 54(2):322-33.

33. Rau KK, Johnson RD, Cooper BY. Nicotinic AChR in subclassified capsaicin-sensitive and -insensitive nociceptors of the rat DRG. J Neurophysiol (2005) 93(3):1358-71. doi:10.1152/jn.00591.2004

34. Shelukhina I, Paddenberg R, Kummer W, Tsetlin V. Functional expression and axonal transport of alpha7 nAChRs by peptidergic nociceptors of rat dorsal root ganglion. Brain Struct Funct (2015) 220(4):1885-99. doi:10.1007/ s00429-014-0762-4

35. Liu L, Pugh W, Ma H, Simon SA. Identification of acetylcholine receptors in adult rat trigeminal ganglion neurons. Brain Res (1993) 617(1):37-42. doi:10.1016/0006-8993(93)90609-Q

36. Alimohammadi H, Silver WL. Evidence for nicotinic acetylcholine receptors on nasal trigeminal nerve endings of the rat. Chem Senses (2000) 25(1):61-6. doi:10.1093/chemse/25.1.61

37. Genzen JR, McGehee DS. Short- and long-term enhancement of excitatory transmission in the spinal cord dorsal horn by nicotinic acetylcholine receptors. Proc Natl Acad Sci U S A (2003) 100(11):6807-12. doi:10.1073/pnas. 11317091001131709100

38. Kohlmeier KA, Soja PJ, Kristensen MP. Disparate cholinergic currents in rat principal trigeminal sensory nucleus neurons mediated by M1 and M2 receptors: a possible mechanism for selective gating of afferent sensory neurotransmission. Eur J Neurosci (2006) 23(12):3245-58. doi:10.1111/j.1460-9568. 2006.04875.x

39. Chen SR, Chen H, Yuan WX, Wess J, Pan HL. Differential regulation of primary afferent input to spinal cord by muscarinic receptor subtypes delineated using knockout mice. J Biol Chem (2014) 289(20):14321-30. doi:10.1074/ jbc.M114.550384

40. Dussor GO, Helesic G, Hargreaves KM, Flores CM. Cholinergic modulation of nociceptive responses in vivo and neuropeptide release in vitro at the level of the primary sensory neuron. Pain (2004) 107(1-2):22-32. doi:10.1016/j. pain.2003.09.022

41. Kilinc E, Guerrero-Toro C, Zakharov A, Vitale C, Gubert-Olive M, Koroleva K, et al. Serotonergic mechanisms of trigeminal meningeal nociception: implications for migraine pain. Neuropharmacology (2016) 116:160-73. doi:10.1016/j.neuropharm.2016.12.024

42. Simonetti M, Fabbro A, D’Arco M, Zweyer M, Nistri A, Giniatullin R, et al. Comparison of P2X and TRPV1 receptors in ganglia or primary culture of trigeminal neurons and their modulation by NGF or serotonin. Mol Pain (2006) 2:11. doi:10.1186/1744-8069-2-11

43. Zakharov A, Vitale C, Kilinc E, Koroleva K, Fayuk D, Shelukhina I, et al. Hunting for origins of migraine pain: cluster analysis of spontaneous and capsaicin-induced firing in meningeal trigeminal nerve fibers. Front Cell Neurosci (2015) 9:287. doi:10.3389/fncel.2015.00287 
44. Marszalek JR, Williamson TL, Lee MK, Xu Z, Hoffman PN, Becher MW, et al. Neurofilament subunit NF-H modulates axonal diameter by selectively slowing neurofilament transport. J Cell Biol (1996) 135(3):711-24. doi:10.1083/jcb.135.3.711

45. Artico M, Cavallotti C. Catecholaminergic and acetylcholine esterase containing nerves of cranial and spinal dura mater in humans and rodents. Microsc Res Tech (2001) 53(3):212-20. doi:10.1002/jemt.1085

46. Vilotti S, Vana N, Van den Maagdenberg AM, Nistri A. Expression and function of calcitonin gene-related peptide (CGRP) receptors in trigeminal ganglia of R192Q Cacnala knock-in mice. Neurosci Lett (2016) 620:104-10. doi:10.1016/j.neulet.2016.03.046

47. Zhang XL, Albers KM, Gold MS. Inflammation-induced increase in nicotinic acetylcholine receptor current in cutaneous nociceptive DRG neurons from the adult rat. Neuroscience (2015) 284:483-99. doi:10.1016/j.neuroscience. 2014.10.018

48. Steen KH, Reeh PW. Actions of cholinergic agonists and antagonists on sensory nerve endings in rat skin, in vitro. J Neurophysiol (1993) 70(1): 397-405.

49. Bernardini N, Sauer SK, Haberberger R, Fischer MJ, Reeh PW. Excitatory nicotinic and desensitizing muscarinic (M2) effects on C-nociceptors in isolated rat skin. J Neurosci (2001) 21(9):3295-302.

50. Sekizawa SI, Tsubone H. Nasal receptors responding to noxious chemical irritants. Respir Physiol (1994) 96(1):37-48. doi:10.1016/0034-5687(94) 90104-X

51. Sucher NJ, Cheng TP, Lipton SA. Neural nicotinic acetylcholine responses in sensory neurons from postnatal rat. Brain Res (1990) 533(2):248-54. doi:10.1016/0006-8993(90)91346-I

52. Genzen JR, Van Cleve W, McGehee DS. Dorsal root ganglion neurons express multiple nicotinic acetylcholine receptor subtypes. JNeurophysiol (2001) 86(4):1773-82.

53. Keiger CJ, Walker JC. Individual variation in the expression profiles of nicotinic receptors in the olfactory bulb and trigeminal ganglion and identification of alpha2, alpha6, alpha9, and beta3 transcripts. Biochem Pharmacol (2000) 59(3):233-40. doi:10.1016/S0006-2952(99)00326-3

54. Albers KM, Zhang XL, Diges CM, Schwartz ES, Yang CI, Davis BM, et al. Artemin growth factor increases nicotinic cholinergic receptor subunit expression and activity in nociceptive sensory neurons. Mol Pain (2014) 10:31. doi:10.1186/1744-8069-10-31

55. Smith NJ, Hone AJ, Memon T, Bossi S, Smith TE, McIntosh JM, et al. Comparative functional expression of nAChR subtypes in rodent DRG neurons. Front Cell Neurosci (2013) 7:225. doi:10.3389/fncel.2013.00225

56. Cao XH, Byun HS, Chen SR, Pan HL. Diabetic neuropathy enhances voltage-activated $\mathrm{Ca}^{2+}$ channel activity and its control by M4 muscarinic receptors in primary sensory neurons. J Neurochem (2011) 119(3):594-603. doi:10.1111/j.1471-4159.2011.07456.x

57. Nandigama R, Bonitz $M$, Papadakis $T$, Schwantes $U$, Bschleipfer $T$, Kummer W. Muscarinic acetylcholine receptor subtypes expressed by mouse bladder afferent neurons. Neuroscience (2010) 168(3):842-50. doi:10.1016/j. neuroscience.2010.04.012

58. Li DP, Chen SR, Pan YZ, Levey AI, Pan HL. Role of presynaptic muscarinic and $\mathrm{GABA}(\mathrm{B})$ receptors in spinal glutamate release and cholinergic analgesia in rats. J Physiol (2002) 543(Pt 3):807-18. doi:10.1113/jphysiol.2002.020644

59. Strassman AM, Weissner W, Williams M, Ali S, Levy D. Axon diameters and intradural trajectories of the dural innervation in the rat. J Comp Neurol (2004) 473(3):364-76. doi:10.1002/cne.20106

60. Theoharides TC, Donelan J, Kandere-Grzybowska K, Konstantinidou A. The role of mast cells in migraine pathophysiology. Brain Res Brain Res Rev (2005) 49(1):65-76. doi:10.1016/j.brainresrev.2004.11.006

61. Levy D. Migraine pain, meningeal inflammation, and mast cells. Curr Pain Headache Rep (2009) 13(3):237-40. doi:10.1007/s11916-009-0040-y

62. Smith JH, Butterfield JH, Cutrer FM. Primary headache syndromes in systemic mastocytosis. Cephalalgia (2011) 31(15):1522-31. doi:10.1177/ 0333102411421683

63. Levy D, Kainz V, Burstein R, Strassman AM. Mast cell degranulation distinctly activates trigemino-cervical and lumbosacral pain pathways and elicits widespread tactile pain hypersensitivity. Brain Behav Immun (2012) 26(2):311-7. doi:10.1016/j.bbi.2011.09.016

64. Munoz-Cruz S, Mendoza-Rodriguez Y, Nava-Castro KE, Yepez-Mulia L, Morales-Montor J. Gender-related effects of sex steroids on histamine release and FcepsilonRI expression in rat peritoneal mast cells. J Immunol Res (2015) 2015:351829. doi:10.1155/2015/351829

65. Durham PL, Russo AF. Stimulation of the calcitonin gene-related peptide enhancer by mitogen-activated protein kinases and repression by an antimigraine drug in trigeminal ganglia neurons. J Neurosci (2003) 23(3):807-15.

66. Giniatullin R, Di Angelantonio S, Marchetti C, Sokolova E, Khiroug L, Nistri A. Calcitonin gene-related peptide rapidly downregulates nicotinic receptor function and slowly raises intracellular $\mathrm{Ca}^{2+}$ in rat chromaffin cells in vitro. J Neurosci (1999) 19(8):2945-53.

67. Fabbretti E, D’Arco M, Fabbro A, Simonetti M, Nistri A, Giniatullin R. Delayed upregulation of ATP P2X3 receptors of trigeminal sensory neurons by calcitonin gene-related peptide. J Neurosci (2006) 26(23):6163-71. doi:10.1523/ JNEUROSCI.0647-06.2006

Conflict of Interest Statement: The authors declare that the research was conducted in the absence of any commercial or financial relationships that could be construed as a potential conflict of interest.

Copyright (c) 2017 Shelukhina, Mikhailov, Abushik, Nurullin, Nikolsky and Giniatullin. This is an open-access article distributed under the terms of the Creative Commons Attribution License (CC BY). The use, distribution or reproduction in other forums is permitted, provided the original author(s) or licensor are credited and that the original publication in this journal is cited, in accordance with accepted academic practice. No use, distribution or reproduction is permitted which does not comply with these terms. 